\title{
Um século à espera de regras
}

\section{HELOÍSA RODRIGUES FERNANDES}

À memória do meu pai, Florestan Fernandes, com quem aprendi a sonhar que a sociologia e o socialismo podem nos ajudar a construir um século melhor

RESUMO: Ao comemorar cem anos da publicação de uma das obras de fundação da Sociologia, As Regras do método sociológico, o artigo retoma a herança durkheimiana problematizando especialmente um dos seus principais legados aos habitantes desse século XX: o conceito de anomia.

UNITERIMOS:

teoria sociológica, modernidade, crise, anomia.

$\mathrm{S}$ vésperas do próximo milênio, a Sociologia comemora seus cem anos das Regras do Método Sociológico, essa obra que se tornou um marco de referência da teoria sociológica e, provavelmente, um marco ainda mais decisivo à medida que o século XX se encarregou de ir erodindo e fragilizando seus principais pontos de sustentação. Afinal, como poderia haver, hoje, uma crise do paradigma dominante se este não estivesse tão bem representado por obras como esta ${ }^{1}$ ? $\mathrm{O}$ fato é que as Regras construíram uma comunidade de leitores que souberam reconhecê-lo como um clássico da Sociologia, embora seja duvidoso que não tenham feito senão responder ao que lhes demandava um estilo com tão poucas dúvidas e tantas certezas. Afinal, uma das regras afirma que o ofício de sociólogo começa pela definição, o que não deixa de ser uma boa garantia de que as respostas não serão perturbadas pelas perguntas.

Um estilo saiu em busca de seus sujeitos e os foi construindo segundo as várias conjunturas teóricas que marcaram o campo sociológico ${ }^{2}$. Não é improvável que, hoje, quando comemora seu primeiro século, a obra seja reconhecida como ocupante desse ambíguo lugar que reservamos aos textos

Esse trabalho foi apresentado no VII Congresso Brasileiro de Sociologia promovido pela Sociedade Brasileira de Sociologia, realizado na Universidade Federal do Rio de Janeiro de 4 a 6 de setembro de 1995.

Professora do Departamento de Sociologia da FFLCH-USP 
reverenciados. Nem tesouro de enigmas a serem decifrados, nem desafio à imaginação sociológica, continuaria lida e relida, mais especialmente, sob o peso de exigências imperativas como a docência, por exemplo. As Regras teriam se tornado o que quiseram ser: texto básico à formação das novas gerações de sociólogos que só o serão passando pela leitura ao menos do seu famoso primeiro capítulo ${ }^{3}$. Estranha maneira da obra de um fundador da Sociologia continuar produzindo filiação, embora a herança pareça ter assumido valor mais de relíquia do que de espólio cobiçado e disputado ${ }^{4}$. Talvez fundador não seja, necessariamente, fecundador, o que ajudaria a compreender não só a espantosa ausência de lutas fratricidas em torno da herança como a igualmente surpreendente maneira de pensar a obra durkheimiana como se ela fosse um bloco monolítico, um mero desdobramento e aprofundamento coerente de hipóteses colocadas desde sempre ${ }^{5}$. Destino que não deixa de ser paradoxal se recordarmos que esse lutador fez da Sociologia uma causa ${ }^{6}$ a ser defendida em campo de batalha (Durkheim, 1963a, p. XVIII).

Não por acaso a Sociologia é definida nas Regras como esse modo de pensar (cf. Durkheim, 1963a, p. XXXII) que se declara disposto a "penetrar o desconhecido"(p.XXI) desde que devidamente protegido pelas armas da cautela, da vigilância e da suspeita. É a cautela que obriga o método a ser essa abordagem que adentra o desconhecido a partir do que é mais imediatamente exterior constrangendo a acreditar que o avanço gradual é a única estratégia capaz de ir acuando cada vez mais de perto essa realidade fugidia (cf. Durkheim, 1963a, p. 42). É a vigilância que justifica o método de observação meticulosa que não quer deixar escapar nada pois um só fato despercebido arrisca colocar tudo em dúvida (cf. p. 124). É a suspeita desse desconhecido que se apresenta sob aparência mentirosa (cf.p. 56) que fundamenta esse procedimento obrigado a classificar os fatos em normais e anormais (cf. Durkheim, 1963a, cf. p. 57-58).

Cautela, vigilância, suspeita são marcas desse modo de pensar para o qual a verdade está à espera do sujeito que se colocou a procurá-la. As regras não estão aí por acaso: se a verdade é habitante do objeto, os descaminhos devem ser contabilizados nas dívidas da travessia do viajante ${ }^{7}$.

Aprendizes de sociólogos, como não sermos seduzidos por um discurso que nos promete adestrar? Durkheim deixa para o final das Regras o reconhecimento de que se trata mesmo de uma iniciação e que esta nos faz uma única exigência, embora pesada : o método sociológico é esse "ponto de vista disciplinador"(Durkheim, 1963a, p. 133) sob o jugo do qual devemos nos despedir das nossas maneiras de pensar, sentir e agir; dos nossos conceitos, hábitos, prenoções; das nossas sensações e desejos ${ }^{8}$. Sob essa condição de nos exilarmos de nós mesmos, encontramos nas regras um mestre disposto a ensinar como é que se deve fazer para repetir seus próprios passos ${ }^{9}$. Se a sedução pode terminar em desilusão bem pode ser porque a demanda é impossível de satisfazer. Para alguns, porque precipita na angústia de não saber se a dívida foi definitivamente paga ou se há, ainda, alguma promissória esquecida disposta a nos surpreender desprevenidos. Para outros, porque a 
ascese pode revelar-se asfixiante pois aceitar a repetição condena à condição do eterno aprendiz.

Ascender ao ponto de vista disciplinador desse modo de pensar a Sociologia encontra inúmeras ressonâncias com aquele olhar observador, vigilante e suspeitoso que Foucault encontrou construindo o panóptico (Foucault, 1983) e que um outro campo teórico denominou supereu ${ }^{10}$. Não teria sido o mesmo olhar que inventou as metodologias de distanciamento e de descontaminação que andaram envenenando inúmeras pesquisas do campo sociológico ${ }^{11}$ ?

Bem fez Canguilhem ao concordar com Bachelard: o normal não é um conceito pacífico mas polêmico e, penso eu, defensivamente guerreiro. Se a norma é aquilo que serve para endireitar, "normalizar é impor uma exigência a uma existência, a um dado, cuja variedade e disparidade" (Canguilhem, 1982, p. 211) se the apresentam como um indeterminado que o normal não apenas deprecia e hostiliza como deseja corrigir ou sanear. Uma avaliação, um desejo mas, também, um horizonte. Afinal, nas Regras, a espécie (em determinada fase do seu desenvolvimento) é a norma "e, por conseguinte, nada pode conter de anormal" (Durkheim, 1963a, p. 53). O normal expulsou de si a doença e a morte, essas contingências que não derivam da, nem são engendradas pela, "natureza das coisas", ao menos quando a natureza é normal (p. 53) ${ }^{12}$. O normal, esse inimigo do indeterminado, do múltiplo e do imprevisto constrói-se na recusa da energia criadora do inacabado e da finitude! A intolerância que está no horizonte do conceito é ainda mais assustadora porque assenta-se nessa certeza de que os conceitos são realidades ou, pelo menos, quando pensa que "esta distinção em gêneros e espécies está inscrita na própria realidade" (Aron, 1967, p. 366).

Dessa associação do conceito polêmico com horizonte intolerante nasceu a anomia, esse legado que Durkheim transmitiu aos habitantes da modernidade para que pudessem autorefletir-se numa imagem que lhes desse sentido. Nascida do mundo moderno, a anomia foi aos poucos conquistando o século XX. Hoje, é a vedete da Sociologia; frequienta, e com crescente insistência, as interpretações de outros campos teóricos como, por exemplo, a psicanálise ${ }^{13}$; assina presença quase diária na mídia e começa a invadir a linguagem do cotidiano. Ao completar seu primeiro século, talvez já seja possível dizer que, sem a anomia, esse mundo seria ainda mais confuso, incógnito ${ }^{14}$. Nem é improvável, aliás, que tenha vindo para substituir essa espécie de vácuo de sentido em que ficamos à medida que foi se erodindo a crença de que os conflitos da modernidade seriam os portadores da energia necessária à realização dos grandes projetos de emancipação, como o socialista. Nesse caso, a anomia teria passado a ocupar o lugar de onde foi desalojada a autonomia. Desce utopia, sobe anomia. Não é por acaso que o sucesso da carreira da anomia tenha ficado atrelado ao horizonte crescentemente intolerante desse final de milênio. Curiosamente, ainda mais intolerante do que o fora no horizonte do seu próprio criador! 
Essa é uma longa história da qual não vou além das pinceladas. Afinal, Durkheim é esse habitante da modernidade que passou a se perguntar comoé que o impossível - uma sociedade de indivíduos, esses seres desalojados e desenraizados -é possível! Aliás, é porque foram expulsos da tradição que ganharam essa liberdade de colocar-se a querer saber como a sociedade faz laço social; quais os elos que a modernidade constrói para "nos prender à vida" (Durkheim, 1963, p. 87) e à própria sociedade. É bem possível que a pergunta já nascesse envenenada na suspeita de que o mal-estar da modernidade estivesse sendo alimentado pela própria configuração desse laço. Nesse caso, a crença de que a "normalidade está nas próprias coisas" (Durkheim, 1963a, p. 68) bem poderia ser uma defesa necessária.

Nem é improvável, aliás, que o percurso da obra durkheimiana seja esse atestado, crescentemente irrefutável, do infundado daquela crença. Afinal, quando ainda é recém-nascida, a anomia retém os traços da sua matriz otimista. Na Divisão do Trabalho Social, a sociedade moderna, análoga ao corpo humano, diferencia-se internamente em órgãos-funções mutuamente dependentes e a relação natural dos órgãos entre si é de cooperação e de solidariedade orgânica: "pode-se dizer a priori que o estado de anomia é impossível sempre que os órgãos solidários estejam em contato bastante e suficientemente prolongado" (Durkheim, 1978, p. 98). Os casos anômicos que a sociedade moderna apresenta - a anarquia das ciências sociais e morais; as crises econômicas e 0 antagonismo entre patrões e empregados - denunciam a carência de regras que regularizem as relações, tornando-as solidárias. $\mathrm{O}$ primeiro conceito de anomia é coerente com um diagnóstico social que não exige qualquer intervenção do sociólogo, pois o necessário "sentimento de mútua dependência" brotará, espontaneamente, pela própria "força das coisas", e o tempo, pouco a pouco, terminará a "obra de consolidação" (Durkheim, 1978, p. 98). A unidade das ciências realizar-se-á por si mesma; a produção terminará encontrando sua justa medida; com o tempo, o conflito de interesses entre patrões e operários encontrará seu ponto de equilíbrio (cf. Durkheim, 1978 , p. $99-100)^{15}$.

Anomia, na primeira elaboração do conceito, é o que permite diagnosticar os conflitos, antagonismos e crises da sociedade moderna como anormais e excepcionais, muito embora, no limite da "plasticidade" da sociedade, e graças à própria "força das coisas", prometam tender espontaneamente à normalidade. Anomia designa as perturbações que afetam uma etapa da maturação do organismo social na linha de uma evolução, ainda não encerrada, em direção à solidariedade orgânica: significa essa "fase de desordem ou de anarquia no curso da evolução" natural (Lacroix, 1984, p. 126). Ademais, é o significante que associa conflito à desordem e, esta, ao que é efêmero e provisório.

Nas Regras, o conceito de anomia nem aparece. Ainda assim, pode ser pressentido nos amplos contornos da anormalidade. Uma mudança decisiva em relação à Divisão do Trabalho está no aparecimento da idéia de que a 
FERNANDES, Heloísa Rodrigues. Um século à espera de regras. Tempo Social; Rev. Sociol. USP, S. Paulo, 8(1): 71-83, maio de 1996.

distinção normal/patológico constrói o diagnóstico da agora necessária intervenção terapêutica. Portanto, já não domina a mesma confiança no amadurecimento espontâneo do corpo social, nem nas propriedades curativas do desenrolar do próprio tempo. Distinguir a saúde - o que é como deveria ser - da doença - o que deveria ser diferente do que é - tornou-se esse critério objetivo de um procedimento que acredita ser necessário intervir para prevenir, ou sanar, as doenças sociais (Durkheim, 1963a, p. 69).

Ainda assim, quem sabe porque o normal é o tipo médio, esse tipo suficientemente amplo para ser o mais freqüente e geral, o conceito preserva um horizonte de tolerância (Fernandes, F., 1967, p. 124-134). Daí a conservação da tese, que já estava na Divisão do trabalho, de que "o enfraquecimento (...) dos sentimentos coletivos para com os objetos coletivos nada tem de anormal" porque, ao contrário, esse enfraquecimento corresponde ao fortalecimento mesmo do tipo de sociedade de solidariedade orgânica (cf. Durkheim, 1963a, p. 57-58, nota 3). Ao mesmo tempo, esse enfraquecimento dos sentimentos coletivos é sintoma de que eles se preservam no estado de "maleabilidade necessária" para adquirir uma nova forma (cf. Durkheim, 1963a, p. 65). Maleabilidade, plasticidade, flexibilidade são condições da esperada mudança social e só podem existir se os sentimentos coletivos possuírem uma energia moderada e se a autoridade da consciência moral não for excessiva (cf. Durkheim, 1963a, p. 65). Mais ainda, a indeterminação progressiva da consciência social é condição da proliferação da diversidade de gostos e de aptidões e das divergências individuais (cf. Durkheim, 1963a, p. 86-87).

É bem por isso que o crime é normal, não só porque seria impossível uma sociedade onde ele inexistisse (cf. Durkheim, 1963a, p. 64), como porque o próprio crime é sintoma de que a sociedade não está cristalizada mas conservou a maleabilidade necessária para poder assumir formas novas (cf. Durkheim, 1963a, p. 65). Muitas vezes, aliás, o crime é “antecipação da moral que está por vir, um encaminhamento para o que tem que ser" ( Durkheim, $1963 \mathrm{a}$, p. 65) ${ }^{16}$. Eis porque não há o que comemorar quando o crime desce abaixo do nível médio pois a própria queda desse índice seria um sintoma do enrijecimento da forma social; tampouco, podemos pensar que a punição seja um remédio, pois o crime não é doença (Durkheim, 1963a, p. 67).

Contudo, a anomia que se apresenta para diagnosticar um dos tipos de suicídio é de um bem outro estatuto. Agora, é o indivíduo que "escapa ao jugo da sociedade" quando esta, perturbada pelos ciclos de recessão ou de prosperidade econômica, encontra-se provisoriamente incapacitada para exercer sua ação de colocar freios às paixões humanas. "Todas as classes são envolvidas porque não existe mais uma ordem estabelecida", diz Durkheim (1978, p. 119). Anomia é, então, o diagnóstico do corpo doente, e não mais das relações dos órgãos entre si. Ademais, não deriva da inexistência de regras de intercâmbio mas da ausência de freios. Já não indica a desordem de uma etapa no curso de uma evolução progressiva e automática em direção à solidariedade orgânica mas é o mal que ameaça a sociedade moderna. 
Anomia, agora, indica o relaxamento da inscrição da sociedade no psiquismo. O termo "consciência coletiva deixa de designar as crenças e os sentimentos comuns próprios apenas das sociedades primitivas" (Lacroix, 1984, p. 124), mesmo porque é essa consciência coletiva que não está suficientemente presente nos indivíduos da sociedade moderna, colocandolhes freios. Anomia tornou-se um diagnóstico do estado das paixões humanas. Um estado apaixonado caracterizado pela dissolução, ou relaxamento, dos freios da consciência coletiva, dando passagem às ambições, às cobiças e às aspirações. "Tem-se sede de coisas novas, de alegrias desconhecidas, de sensações inconfessáveis"(Durkheim, 1978, p. 120). Abertura do horizonte ao infinito, eis o que desperta, para Durkheim, "esse espírito de rebelião que é a própria fonte da imoralidade" (1963a, p. 119).

Anomia é o diagnóstico das paixões humanas quando estas, sob certas condições sociais, rompem os freios, destravam as portas e se afirmam exaltadas, ameaçando a sobrevivência da ordem. A terapia já não confia, otimista, no retorno espontâneo à normalidade, pela ação das próprias coisas, e já não há como dar tempo ao tempo. O mal pede a intervenção enérgica dos bons remédios: controle, contenção, disciplina ${ }^{17}$. Moralização das crianças, quando ainda há tempo, nas escolas públicas e, também o freio moralizador da pobreza, pois esta, obrigando a manter as aspirações sob o mais rígido controle, "prepara para aceitar docilmente a disciplina coletiva"(Durkheim, 1978, p. 119) ${ }^{18}$.

Paixões fervilhantes, arrombando paredes e descortinando horizontes, é por aí que, agora, irrompe a anomia. É bem verdade que, sob o nome da mesma doença, ficaram imbricados sintomas múltiplos e, até, discrepantes - avidez, corrupção, roubo, assassinato, greve, rebelião, revolução. De todo modo, Durkheim parece ter se concentrado no que considerou essencial: as paixões humanas em "estado de eretismo natural e apenas por isso a vitalidade geral é mais intensa" (Durkheim, 1978, p. 118). Paixões eroticamente excitadas, em estado de ereção; essa seria, agora, a causa da anomia, doença que ameaça a sobrevivência do "corpo social" exigindo a intervenção enérgica das duchas de água fria da educação (disciplina) moral.

Parsons tem razão: é graças ao tratamento dado à anomia em $O$ Suicídio que Durkheim começa a elaborar uma teoria sociológica onde o estatuto do social já não é, como antes, o de uma categoria residual e negativa - isso que não seria nem biológico, nem psicológico (Parsons, 1968, p. 441442 e p. 449-470). O social passa a ser a estrutura das regras normativas de uma sociedade: esse conjunto de valores e crenças, maneiras de pensar, sentir e agir coletivas que só são ativas porque, e enquanto, estão psiquicamente inscritas, sendo reconhecidas como detentoras de autoridade moral ${ }^{19}$. Em suma, o social tornou-se uma ordem normativa internalizada. As regras coletivas fazem laço social porque, "tornando-se internas, subjetivas, $o$ indivíduo 'identifica-se' com elas. Na terminologia de Freud, são 'interiorizadas' para formar um supereu" (Parsons, 1968, p. 480 e nota 21). 
FERNANDES, Heloísa Rodrigues. Um século à espera de regras. Tempo Social; Rev. Sociol. USP, S. Paulo, 8(1): 71-83, maio de 1996.

É por isso que, quando esse controle é perturbado ou desorganizado, a conduta dos habitantes dessa sociedade torna-se igualmente desorganizada e caótica. O que é a anomia, agora, senão este estado de desorganização social que é o efeito da deterioração do controle das normas sobre as condutas? (cf. Parsons, 1968, p. 470).

Portanto, Durkheim teria encontrado um tipo de resposta à pergunta que formulara à modernidade. Se o que faz laço social é o Outro - conjunto de regras normativas - que se torna psiquicamente ativo e atuante porque é parte constitutiva da personalidade ${ }^{20}$, a anomia (desordem) tornou-se o sintoma do mal-estar decorrente do enfraquecimento ou degradação da encarnação psíquica do Outro, que é quando o laço social se desfaz na violência ou, como prefere Parsons, na guerra de todos contra todos ${ }^{21}$.

A maioria dos críticos desse novo conceito de social realçam que ele teria o efeito de transformar o conformismo em virtude moral suprema (Parsons, 1968, p. 485-486). Contudo, o preço que se paga por essa concentração nos efeitos é o de manter recalcados os pressupostos que permitiram a construção mesma do conceito.

Um dos pressupostos e, talvez, o principal, é uma ficção: esse indivíduo abstrato, esse ser bárbaro, de paixões e apetites infinitos, desmedidos, desmesurados. Esse monstro de natureza indômita e indomável, de onde emergem as forças centrífugas da sociedade moderna. Quem senão ele justifica o segundo pressuposto: só um Outro austero e rígido, internamente ativo e atuante, é capaz de construir as fortalezas encarregadas de aprisionar o monstro.

$\mathrm{O}$ atestado de atualidade desses pressupostos na teoria sociológica pode ser encontrado em análise recente onde Dahrendorf sustenta que a sociedade moderna desse final do século vinte está a caminho da anomia porque a impunidade penal crescente é responsável pelo agravamento da imprevisibilidade das condutas individuais (Dahrendorf, 1987, p. 11-46). Embora seu horizonte seja ainda mais intolerante que o do último Durkheim ${ }^{22}$, o trabalho de Dahrendorf traz uma enorme contribuição à concepção durkheimiana: já não é mais necessário apelar ao ser primitivo e bárbaro; tudo emana, agora, de uma paradoxal "sociabilidade insociável do homem" (Dahrendorf, 1987, p. 45-46) 23. $^{23}$.

O terreno onde estão fincados esses pressupostos foi muito bem precisado, embora acriticamente, por Parsons: de um lado, está o desejo, indisciplinado e caótico; do outro, a regra normativa. "Para que a concepção de controle normativo possa ter sentido (...) estes dois elementos devem ser radicalmente heterogêneos em princípio" (Parsons, 1968, p. 471). Se o desejo não tivesse "essa qualidade centrífuga, intrinsecamente caótica, não haveria, em absoluto, necessidade de controle" (p. 471). É por isso que a anomia é "precisamente este estado de desorganização no qual o controle das normas sobre a conduta (...) deteriorou-se. Seu limite extremo é o estado de 'individualismo puro' que é para Durkheim, como o foi para Hobbes, a guerra de todos contra todos" (Parsons, 1968, p. 471) ${ }^{24}$. 
Acentuar os pressupostos bem pode ser uma brecha para a emergência do que permaneceu recalcado. Afinal, se é o Outro que nos constitui, por que será que esses habitantes impetuosos, excessivos, desmedidos, não poderiam estar obedecendo, e muito bem, a um mandato de gozo que vem do Outro? Por que será que esse estado de "individualismo puro" precisaria ser atribuído à "natureza indomável do homem" ou à sua "sociabilidade insociável" 25 ? Anomia como produção do Outro, não estaria aí o impensado? Nesse caso, exigir que se reduza o espaço de incerteza e de imprevisão, não apenas agravaria a intolerância, como destruiria a já tão curta distância entre desejo e gozo ${ }^{26}$.

Quem sabe a anomia seja mesmo um sintoma do mal-estar na modernidade ? Sintoma dessa impossibilidade de habitar uma cultura que nos demanda como indivíduos - seres indivisos, monádicos, desterrados e "livres como pássaros" - ao mesmo tempo que não cessa de nos cobrar porque obedecemos tão bem ao seu mandato! Como enfrentar o impensado sem admitir a hipótese de que a anomia não derive do enfraquecimento de um conjunto de valores comuns mas, ao contrário, do fortalecimento massivo, e crescentemente exclusivo, daqueles valores que construíram a modernidade. Será que o cada um por si, que o conceito de anomia evoca, não emanaria dos "bons e velhos ideais oitocentistas do mercado, do direito e da democracia parlamentarista"? (Rajchman, 1993, p. 169).

Quem sabe a anomia não seja esse imaginário ao qual devemos duas das nossas crenças mais queridas: a de que a fonte do desejo é inesgotável e a de que o próprio desejo é imortal, pois ressurge sempre, independentemente do desejo do Outro ${ }^{27}$, em cada pequeno monstro recém-nascido!

Afinal, se a "nossa cultura individualista já nasceu culpada e continua convencida de ser uma progressiva degeneração, um declínio do que teria sido, no passado, uma idade de ouro onde o bem comum seria o supremo valor para todos" (Calligaris, 1994, p. 3), não por acaso permaneceu cobrando a pedagogia por seu fracasso na domesticação do monstro, por sua incapacidade de ser eficaz no trabalho de fazer inscrever o Outro na criança! Não esse Outro frouxo qualquer, mas um Outro de verdade: esse que saberia mesmo como nos impor regras, único capaz de completa previsibilidade e de permanente punibilidade ${ }^{28}$. Não foi porque lastimamos tanto essa "ausência de pais", porque "nos queixamos mesmo tanto disto que estes pais não deixaram de ressurgir sob todas as formas, como vimos florescer desde o início deste século"? (Pommier, 1992, p. 24) ${ }^{29}$.

Um século à espera de regras, nostálgico desse Outro de verdade que, ele sim, saberia o que fazer. Será que essa ficção coletiva não nos teria poupado reconhecer que não é que esse Outro não se importe conosco - afinal, se ele se importasse, sempre poderíamos supor como fazer para enternecê-lo ou emocioná-lo, - e o narcisismo o que é senão a suposição de poder cativar o seu olhar - mas que ele não exista (cf. Melman, 1991, p. 78) ou, mais propriamente, só exista segundo nossa demanda e na animação dessas vozes 
FERNANDES, Heloísa Rodrigues. Um século à espera de regras. Tempo Social; Rev. Sociol. USP, S. Paulo, 8(1): 71-83, maio de 1996.

que continuam tecendo nossa fala?

Mas, se nada quisermos saber disso, como é que ainda poderemos inventar um novo modo de pensar capaz de colocar a "questão da legalidade, onde existe apenas o domínio da lei; a questão do governo, onde existe apenas o exercício do poder, e a questão da auto-invenção, onde existe apenas o funcionamento do saber"? (Rajchman, 1993, p. 170).

\section{Recebido para publicação em outubro/1995}

FERNANDES, Heloísa Rodrigues. A whole century waiting for rules. Tempo Social; Rev. Sociol. USP, S. Paulo, 8(1): 71-83, May 1996.

ABSTRACT: On the occasion of the celebration of one of the founding works of Sociology, The rules of sociological method, this paper reinstates the heritage of Durkheim, with special emphasis on one of its main contributions to the $20^{\text {th }}$ century: the concept of anomy.

UNITERIMOS sociological theory, modernity, crisis, anomy.

\section{Notas}

${ }^{1}$ Interpretação instigante e criativa, da crise desse paradigma, encontra-se em Santos (1988).

${ }^{2} \mathrm{O}$ antagonismo ao indeterminado pode ter sido uma das vias através das quais o estruturalismo, por exemplo, marca uma conjuntura teórica de franca recuperação da obra durkheimiana, de Lévi-Strauss a Lacan. Marxistas das décadas de 60 a 80, quantos de nós não encontramos inúmeros laços de consangüinidade com Durkheim! Afinal, bastava substituir a determinação das "condições sociais de existência" durkheimiana, por determinação do modo de produção; a determinação do "meio social interno", por determinação de classe; a "consciência coletiva", por consciência de classe, etc.!

3 “Que é fato social?". Sintomaticamente, a interrogação não é do autor, mas dos seus presumidos leitores, aos quais, aliás, Durkheim apresta-se a responder.

${ }^{4}$ Penso no contraste com as heranças deixadas por outros fundadores como Freud, Marx, etc.

${ }^{5}$ A exceção mais notável é a de Talcott Parsons (1968), que analisou a obra durkheimiana realçando as diferenças (impasses e deslocamentos) entre a concepção do social presente no $A$ divisão do trabalho social e aquela que se tornaria dominante especialmente a partir do $O$ suicídio. Para Parsons, as diferenças tornar-se-iam tão profundas que afetariam decisivamente inúmeros fundamentos das Regras, muito marcadas, ainda, pela Divisão do trabalho social. Assim, a externalidade e o mundo social externo coercitivo, que fundamentam sua regra mais famosa (os fatos sociais devem ser observados como coisa), tornar-se-iam internalidade e realidade psíquica moral internalizada (Parsons, 1968, p. 484-5). Bernard Lacroix, por sua vez, sustenta que teria havido um verdadeiro corte epistemológico na obra durkheimiana (1984, p. 100-237). Ainda assim, são exceções à tendência dominante que continua a apresentar a obra como uma totalidade monolítica e homogênea.

${ }^{6}$ Veja-se, especialmente, Ortiz (1989). 
${ }^{7}$ Diferença enorme, portanto, com uma outra perspectiva para a qual a verdade não é um resultado que vem no final de um processo de pensamento, mas uma experiência que se torna a condição de possibilidade do pensar, e que está tão bem explicitada por Arendt (1995); texto igualmente instigante pela explicitação da hipótese de que uma das raízes da modernidade seria a desconfiança em relação aos sentidos e, em especial, ao senso comum, como "mundo comum".

${ }^{8}$ Os efeitos epistemológicos da desqualificação do desejo na geração do conhecimento são discutidos por Gomes (1994).

${ }^{9}$ Quantos de nós, de filiações outras, já não lastimamos que outros clássicos nos tivessem deixados carentes de textos de idêntico estatuto!

${ }^{10}$ No curso de Introdução à Sociologia, quando a Faculdade de Filosofia da Universidade de São Paulo ainda morava na Maria Antonia, aprendíamos com o professor Luiz Pereira que a perspectiva durkheimiana era a de um "imenso e onisciente olho boiando acima da realidade". Mas Parsons, que eu saiba, foi dos poucos a reconhecer, embora de passagem e sem comentários, que, se usássemos a conceituação de Freud, o sistema normativo durkheimiano seria "interiorizado" para formar o supereu (cf. 1968, p. 480, nota 21). Lacroix opta por uma outra via quando afirma que a obra durkheimiana "em seu desenvolvimento, encontra-se dominada pela lógica antagônica do supereu” (1984, p. 190).

${ }^{11}$ É verdade que as Regras nem recomendariam essas pesquisas de campo. Afinal, se "os caracteres de constância e regularidade são sintomas da sua objetividade" (Durkheim, 1963a, p. 26), o objeto por excelência da Sociologia encontra-se nas "formas mais cristalizadas do social, como o direito" (p. 41-42). Ademais, as Regras enfatizam a necessidade de utilizar "artifícios metodológicos" (entre os quais, a estatística) como procedimentos propiciadores do "isolamento", "dissociação" e "descontaminação" (p. 7).

${ }^{12}$ É curioso que Parsons concorde que, para um fisiólogo, seria inadmissível aceitar que a enfermidade seja acidental, como quer Durkheim. Ainda assim, para ele, Parsons, a afirmação durkheimiana não seria inadmissível mas apenas "plena de ambigüidades"! (1968, p. 465)

${ }^{13}$ Entre os de maior reconhecimento na Sociologia, Castoriadis (1987).

${ }^{14}$ Parafraseio Ianni : "o Mundo Moderno depende da Sociologia para ser explicado, para compreender-se. Talvez se possa dizer que, sem ela, esse Mundo seria mais confuso, incógnito" (Ianni, 1989, p. 8).

15 É verdade que o "tempo não tem nenhuma ação" sobre a desigualdade ainda muito grande das condições exteriores de luta entre patrões e operários. Mas essa é uma verdade que não transtorna a interpretação permanecendo, aliás, muito bem acomodada em mera nota de rodapé (cf. Durkheim, 1978, p. 99, nota 2).

${ }^{16}$ Nas Regras, Durkheim recorre ao exemplo de Sócrates, criminoso segundo o direito ateniense da sua época, embora antecipador de uma moral e de uma fé novas (cf. Durkheim, 1963a, p. 65-66).

17 Já não domina aquela "relação positivista com o que existe, bom ou mal", que Adorno e Horkheimer realçaram como sendo o ideal de fundação da sociologia durkheimiana (1969, p. 17).

${ }^{18}$ Para Durkheim, a pobreza é a "melhor das escolas para ensinar o homem a conter-se" ; é por isso que pobres, e países pobres, estariam mais protegidos contra o suicídio (Durkheim, 1978, p. 119). Hipóteses que entrariam em contradição com uma pesquisa recentemente publicada no British Medical Journal: onze mil pacientes britânicos foram acompanhados durante dez anos tendo sido constatado que as tentativas de suicídio nas áreas mais pobres da cidade foram de três a oito vezes maiores do que nas áreas ricas (Folha de S. Paulo, 25/7/95, caderno 1, p. 13).

${ }^{19}$ Bem a propósito, Parsons passa a utilizar "comunidade" ou, então, "ordem social", quando quer se referir à sociedade, nessa última concepção durkheimiana (veja-se, por exemplo, 1968, p. 483 e p. 484). Também é pela via da comunidade - especialmente pela função unificadora da religião -, que Jameson acha ter encontrado um impulso utópico na concepção durkheimiana (1981, p. 302). 

maio de 1996.

${ }^{20}$ Tema que trabalhei mais detalhadamente em Sintoma social dominante e moralização infantil (1994). É importante realçar que, no horizonte desse novo conceito de anomia, Durkheim conserva a tese de que o crime é normal. Não obstante, o crime já não é sintoma de que a consciência coletiva teria preservado o estado de maleabilidade e de flexibilidade necessário à mudança social. Agora, limita-se a afirmar que "para a maior parte de seus concidadãos, Cristo e Sócrates foram seres imorais e não tiveram nenhuma autoridade sobre eles"(Durkheim, 1963b, p. 77).

${ }^{21}$ Muitos teóricos da "cultura do narcisismo" recorrem à psicanálise para atribuir a chamada "agonia" da sociedade moderna à degradação do discurso paterno com conseqüente regressão a um supereu ainda mais arcaico e feroz, porque materno (veja-se, por exemplo, Lasch, 1983, p. 215 e 219; Zizek, 1992, p. 73). Penso que é possível encontrar um laço de filiação entre essa teoria e a última concepção durkheimiana de sociedade.

${ }^{22}$ Com a exceção dos "medíocres" e dos "hesitantes", Durkheim nunca acreditou que a punição pudesse ter esse efeito intimidatório presumido por Dahrendorf. Inclusive na última concepção durkheimiana de social, a punição não visa propriamente o criminoso; ela é necessária porque reafirma a força e a autoridade da lei (da consciência coletiva) que o criminoso afrontou; em outros termos, a punição visa aos obedientes mais propriamente que aos criminosos (Fernandes, H., 1994, p. 162-169).

${ }^{23}$ Não deixa de ser curioso que todo argumento de Dahrendorf esteja assentado nessa demanda de previsibilidade exatamente quando o neoliberalismo vem proclamar que estamos condenados às regras do livre mercado; em outros termos, quando a impunidade graças à qual essas regras funcionam, agrava a mais radical imprevisibilidade das nossas mais cotidianas e comezinhas condições de existência!

${ }^{24}$ Uma pista que deixei de explorar foi a de que a anomia bem pode ser um conceito impaciente e, no limite, associológico. Afinal, se a anomia termina sendo atribuída ao "ser bárbaro e primitivo" ou à "sociabilidade insociável do homem", já não é necessário investigar a violência nos seus diversos e diferentes contextos sociais nem, muito menos, há que elaborar conceitos novos que respondam à emergência de novas configurações da violência social.

${ }^{25}$ Leitor de Durkheim, Lacan tem o mérito de ter sido radical: se é o Outro que nos constitui, inclusive o " Trieb (...) é uma verdadeira montagem onde o que é de fonte 'orgânica' só aparece na medida em que é retomado em uma estrutura. É o ponto eminente de valorização da palavra. É ali, mais do que nunca, que a dita estrutura exige a topologia precisa da qual se distinguem, e se articulam, a demanda e o desejo para além da necessidade." (Lacan, 1994, p. 50)

${ }^{26}$ Distinção lacaniana entre gozo, imerso na demanda, alienado ao Outro, sob domínio da pulsão de morte e desejo (desejo que deseja desejar, porque é falta escavada na incompletude). Especialmente a associação gozo/perversão tem enormes ressonâncias com o tema em discussão: "porque toda linguagem é um laço discursivo, não existe tal coisa como um sujeito perverso, e sim sujeitos presos ao modo de gozar da perversão. $E$ na relação performativa com o Outro, imaginariamente apresentado como realidade social ou individual, que se esgota descritiva e valorativamente a definição da perversão. A chamada perversão nada mais é do que a montagem em que os sujeitos, alternadamente, podem ocupar a posição de objeto ou instrumento do gozo do Outro, ou de detentor imaginário do saber que faz o Outro gozar. Este saber onipotente está no núcleo da paixão instrumental (...). Perversa é toda montagem ou toda prática lingüística em que os sujeitos apropriam-se imaginariamente de um saber que reduz o outro a instrumento de gozo da própria montagem. Assim como no vínculo do burocrata nazista com sua vítima; do racista com o discriminado; do violentador com o violentado; do sádico com o masoquista ou, por fim, das almas bem pensantes com os excluídos da 'pólis' moral burguesa" (Costa, 1993, p. 6).

${ }^{27}$ No interior do referencial teórico lacaniano, embora com uma interpretação própria, Piera Aulagnier publicou inúmeros trabalhos nos quais desenvolve a hipótese de que só há desejante graças ao discurso e ao desejo do Outro. Veja-se, por exemplo, Aulagnier (1979).

${ }^{28}$ Por ser paradigmática, a posição de Dahrendorf (1987) merece ser retomada mais detalhadamente. Desde o início, sua abordagem tem forte impacto sobre o leitor porque Dahrendorf evoca memórias do que ele mesmo viveu em Berlim, no final de 1945, quando 
os nazistas já haviam sido derrotados e as forças aliadas ainda não haviam chegado: "esse momento supremo e horrível de absoluta falta de leis" (p. 12) e "absolutamente nenhuma autoridade" (p. 11) em que todos são precipitados nos "tormentos da anomia" (p. 15). Lojas, armazéns e livrarias abandonados são saqueados. Dahrendorf e seu vizinho carregam vinte quilos de carne "para casa", onde sua mãe encarregou-se de prepará-la (p. 12). Curiosa "guerra de todos contra todos" que ainda preserva o significado de casa, onde essa carne pode ser armazenada, sem ser igualmente saqueada! Quanto aos livros que retirou de uma livraria, conserva-os até hoje! Curiosa, também, a idéia de anomia como essa "aberração temporária”(p. 15) em que já não há nenhuma autoridade, mas que, felizmente, é breve pois, logo depois, chegaram os primeiros oficiais russos! (Dahrendorf, 1987, p. 12). A anomia é esse breve período entre o nazismo e a ocupação russa! É por isso que sua interpretação da anomia está construída nesse escandaloso silêncio seja de um, seja do outro. Nenhuma palavra sobre esse momento supremo e horrível em que havia leis e autoridades nazistas; nenhuma palavra, tampouco, sobre os horrores da ocupação! Sob a guarda do poder de Estado, seja ele qual for, Dahrendorf sente-se protegido e é por isso que não há qualquer menção à impunidade do poder do Estado em relação aos cidadãos! A imagem da "guerra de todos contra todos" que a anomia está encarregada de evocar é o que permite recalcar não só a questão da heteronomia como, também, o fato de que as violências mais monstruosas desse século foram organizadas a partir do Estado e por funcionários colocados sob suas ordens! Com a exceção da violência de classe que, para ele, já estaria ultrapassada, Dahrendorf não realça a importância dos grupos sociais organizados, sejam ele bandos, gangues ou máfias. Em suma, a abordagem pela perspectiva da anomia parece precisar sustentar-se na idéia de que a violência emana desse isolado ser "sociável insociável" que ameaça a ordem social.

${ }^{29}$ A anomia, então, bem poderia ser apenas uma das formas assumidas por essa nostalgia de um Outro "de verdade", o que não deixa de dar o que pensar de uma Sociologia nela fundada.

\section{REFERÊNCIASBIBLIOGRÁFCAS}

Adorno,Theodor \& Horkheimer, Max. (1969) La sociedad, lecciones de sociología. Buenos Aires, Proteo.

ArendT, Hannah. (1995) Carta a Mary McCarthy (agosto de 1954). Folha de S. Paulo, 18/06, caderno 5, p. 5.

Aron, Raymond. (1967) Les étapes de la pensée sociologique. Paris, Gallimard.

Aulagnier, Piera. (1979) A violência da interpretação. Rio de Janeiro, Imago.

CAlligaris, Contardo. (1994) Com quanta culpa se faz a modernidade. Folha de S. Paulo, 18/06, caderno 6, p. 3.

CAnguilhem, Georges. (1982) O normal o patológico. Rio de Janeiro, Forense/ Universitária.

Castoriadis, Cornelius. (1987) Psicanálise e sociedade II. In: As encruzilhadas do labirinto. Vol. 2. Rio de Janeiro, Paz e Terra.

Costa, Jurandir Freire. (1993) Psicanalista destronou definição preconceituosa de "perversão". Folha de S. Paulo, 27/04, caderno 4, p. 6.

DAHRENDORF, Ralph. (1987) A lei e a ordem. São Paulo, Instituto Tancredo Neves/Fundação Friedrich Naumann.

DuRKHEIM, Émile. (1963a) As regras do método sociológico. $3^{\text {a }}$ edição. São 
Paulo, Editora Nacional.

. (1963b) L'éducation morale. Paris, Presses Universitaires de France.

. (1978) Divisão do trabalho e suicídio. In: Rodrigues (org.).

Durkheim. Coleção grandes cientistas sociais, $\mathrm{n}^{\circ}$ 1. São Paulo, Editora Ática. p. 73-143.

Fernandes, Florestan. (1967) Fundamentos empíricos da explicação sociológica. São Paulo, Nacional.

FERnANDEs, Heloísa. (1994) Sintoma social dominante e moralização infantil. São Paulo, Escuta/EDUSP.

Foucault, Michel. (1983) Vigiar e punir. Petrópolis, Vozes.

GoMEs, Roberto. (1994) O saber sem desejo (Durkheim e as ciências humanas). Veritas, Porto Alegre, vol. 39, n⿳156, p. 639-660. Dezembro.

IAnNi, Octavio. (1989) A sociologia e o mundo moderno. Tempo Social, São Paulo, vol. 1, n 1, p. 7-27. Departamento de Sociologia, FFLCHUSP.

Jameson, Frederic. (1981) O inconsciente politico. São Paulo, Ática.

LACAN, Jacques. (1994) Entrevista com Jacques Lacan (26/11/1966). Psicanálise e ilusões contemporâneas. Revista da Associação Psicanalítica de Porto Alegre, ano IV, no 10, p. 48-54. Outubro.

LACRoIX, Bernard. (1984) Durkheim y lo político. México, Fondo de Cultura Económica.

LASCH, Cristopher. (1983) A cultura do narcisismo. Rio de Janeiro, Imago.

Melman, Charles. (1991) Pontuações. Curso editado pela Associação Psicanalítica de Porto Alegre, setembro.

ORTIZ, Renato. (1989) Durkheim: arquiteto e herói fundador. Revista Brasileira de Ciências Sociais, ANPOCS, vol. 4, n 11, p. 5-22. Outubro.

PARsons, Talcott. (1968) La Estructura de la acción social. Tomo 1. Madri, Guadarrama.

Pommier, Gérard. (1992) Existiria um sentido psicanalítico da "História"? Palavração, Revista da Biblioteca Freudiana de Curitiba, ano 2, $\mathrm{n}^{0}$ 2, p. 21-29. Outubro.

RajChMAn, John. (1978) Eros e verdade. Lacan, Foucault e a questão da ética. Rio de Janeiro, Jorge Zahar Editor.

SANTos, Boaventura de Sousa. (1988) Um discurso sobre as ciências na transição para uma ciência pós-moderna. Estudos Avançados, São Paulo, vol. 2, n⿳2 2, p. 46-71. Maio-agosto.

ZizeK, Slavoj. (1992) Eles não sabem o que fazem. O sublime objeto da ideologia. Rio de Janeiro, Jorge Zahar Editor. 
FERNANDES, Heloísa Rodrigues. Um século à espera de regras. Tempo Social; Rev. Sociol. USP, S. Paulo, 8(1): 71-83, maio de 1996. 